\title{
Conventional cytogenetic characterization of a new cell line, ACP01, established from a primary human gastric tumor
}

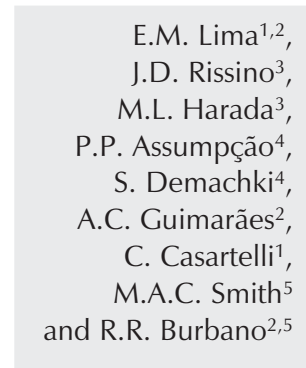

\author{
1Departamento de Genética, Faculdade de Medicina de Ribeirão Preto, \\ Universidade de São Paulo, Ribeirão Preto, SP, Brasil \\ Departamentos de ${ }^{2}$ Biologia, and ${ }^{3}$ Genética, Centro de Ciências Biológicas, \\ Universidade Federal do Pará, Belém, PA, Brasil \\ ${ }^{4}$ Departamento de Patologia e Serviço de Cirurgia, \\ Hospital Universitário João de Barros Barreto, Universidade Federal do Pará, \\ Belém, PA, Brasil \\ ${ }^{5}$ Disciplina de Genética, Departamento de Morfologia, Escola Paulista de Medicina, \\ Universidade Federal de São Paulo, São Paulo, SP, Brasil
}

\section{Correspondence \\ R.R. Burbano \\ Departamento de Biologia \\ CCB, Universidade Federal do Pará \\ Av. Augusto Correia, 1 \\ 66075-900 Belém, PA \\ Brasil \\ Fax: +55-91-211-1601 \\ E-mail: rommel@ufpa.br \\ Research supported by Fundo Estadual de Ciência e Tecnologia do Estado do Pará, Universidade Federal do Pará, CAPES and CNPq (No. 151127/2002-6).}

Publication supported by FAPESP

Received October 10, 2003 Accepted May 25, 2004

\begin{abstract}
Gastric cancer is the second most frequent type of neoplasia and also the second most important cause of death in the world. Virtually all the established cell lines of gastric neoplasia were developed in Asian countries, and western countries have contributed very little to this area. In the present study we describe the establishment of the cell line ACP01 and characterize it cytogenetically by means of in vitro immortalization. Cells were transformed from an intestinal-type gastric adenocarcinoma (T4N2M0) originating from a 48-year-old male patient. This is the first gastric adenocarcinoma cell line established in Brazil. The most powerful application of the cell line ACP01 is in the assessment of cytotoxicity. Solid tumor cell lines from different origins have been treated with several conventional and investigational anticancer drugs. The ACP01 cell line is triploid, grows as a single, non-organized layer, similar to fibroblasts, with focus formation, heterogeneous division, and a cell cycle of approximately $40 \mathrm{~h}$. Chromosome 8 trisomy, present in $60 \%$ of the cells, was the most frequent cytogenetic alteration. These data lead us to propose a multifactorial triggering of gastric cancer which evolves over multiple stages involving progressive genetic changes and clonal expansion.
\end{abstract}

Key words - Cell line ACP01

- Human gastric adenocarcinoma

- In vitro immortalization

- Chromosome 8 trisomy

- Clonal expansion

\section{Introduction}

Gastric carcinoma is the second most common type of malignancy and also the second most common cause of mortality in the world (1,2). In 1999 stomach cancer was responsible for the largest number of deaths caused by neoplasms in Brazil. The State of Pará has a high incidence of this type of neoplasia. The gastric cancer presents the biggest proportional distribution of the total of deaths for cancer in men in the State of 
Pará (25.9\%) (3). Its capital, Belém, is 11th in the number of cases of gastric cancer per inhabitant among all cities of the world with data available on cancer incidence (1).

There are few published cytogenetic studies of gastric carcinoma, with only 128 cases reported to date $(4,5)$. Virtually all of the established cell lines were developed in Asian countries, with western countries having contributed relatively little to this area. The ACP01 cell line described here is the first line of adenocarcinoma cells developed in Brazil. Cytogenetic studies of gastric neoplasia conducted in western nations are rare, mainly due to technical difficulties related to in vitro cell culture (6). Nevertheless, various chromosome alterations have been reported in gastric cancer, involving different chromosomes, such as chromosomes 3, 5, 6, 8, 12, 13, and 17 (7-9).

Gastric cancer cell lines have been used as a biological model to obtain information about the clonal evolution of this malignancy $(6,10,11)$. Yet, in spite of the importance of gastric cancer, relatively few such cell lines are available (12). So far, 59 lines have been cultured, 14 of which were from primary tumors (13-23) and the remainder from secondary tumors or metastases $(10,12$, 14-17). Most of these cell lines (78\%) were isolated in Asia (6).

Clearly, it is necessary to produce more gastric cancer cell lines to allow the study of the phenotypic diversity of stomach neoplasms and to develop models which are adequate for the study of such tumors $(11,16,18)$. We developed and characterized cytogenetically a cell line called ACP 01 from a gastric adenocarcinoma removed from a patient who lived in the State of Pará, Brazil.

\section{Material and Methods}

\section{Sample}

Patient A.M.B., a 48-year-old male of mixed European and African descent, was submitted to subtotal gastrectomy followed by lymphadenectomy, and the material removed from the antrum was analyzed. The patient had not been treated with radiation or chemotherapy. He was previously informed about this study and gave the written informed consent. The study was approved by the Ethics Committee of the Hospital Universitário João de Barros Barreto. The tumor material was used for histopathological study, for tissue culture and for cytogenetic analysis.

\section{Histopathology}

The material was fixed in 10\% formaldehyde, embedded in paraffin, sectioned, and stained with hematoxylin-eosin.

Tissue culture, in vitro immortalization, and morphological cell analysis. Fragments of the surgical specimens, received under sterile conditions, were cut into very small pieces, treated with $0.1 \%$ collagenase IV (Sigma, St. Louis, MO, USA) and added to sterile bottles containing HAM-F10 medium (Sigma) supplemented with $20 \%$ fetal calf serum and antibiotics. Cells were grown at $37^{\circ} \mathrm{C}$. The culture was immortalized in vitro by spontaneous transformation. The morphological analyses of the cell line, which we named ACP01, were carried out using microphotographs of cultures prepared daily, taken with an inverted Axiovert 25 microscope (Zeiss, Jena, Germany), and mitotic activity was determined.

The mitotic index (MI) was calculated using the formula: $\mathrm{MI}=\mathrm{m} / \mathrm{N}$ x 100 , where $\mathrm{m}=$ number of cells in mitosis; $\mathrm{N}=$ number of cells in interphase and number of cells in mitosis; $100=$ percentage factor.

\section{Cryopreservation}

The ACP01 cell line was cryopreserved according to the "previous dehydration" protocol developed in our laboratory. This protocol provided maximum viability of this 
cell line as determined by Trypan blue analysis. The protocol consists of the following steps: I. Dehydration - The cells are removed in a trypsin-EDTA solution and placed in a dehydrating solution (1.2 M sucrose, 20\% fetal calf serum, and 20\% Hanks' solution) for $20 \mathrm{~min}$. II. Freezing - The cells are placed in a cryoprotective solution maintained at $10^{\circ} \mathrm{C}(0.5 \mathrm{M}$ sucrose, $33 \%$ HAM F- 10 medium, $30 \%$ fetal calf serum, and $7 \%$ glycerol), and the temperature is then gradually reduced to $-8^{\circ} \mathrm{C}$ for $4 \mathrm{~h},-20^{\circ} \mathrm{C}$ for $6 \mathrm{~h}$, and to $-60^{\circ} \mathrm{C}$ in liquid nitrogen $\left(\mathrm{N}_{2}\right)$ for $1 \mathrm{~h}$, and the cells are then immersed in liquid $\mathrm{N}_{2}$. III. Thawing - This is done abruptly, subjecting the cells to a drastic temperature change $\left(-96^{\circ}\right.$ to $\left.37^{\circ} \mathrm{C}\right)$, after which they are placed in a rehydrating solution ( $0.3 \mathrm{M}$ sucrose, $30 \%$ fetal calf serum, and 25\% Hanks' solution). After this procedure, the material is washed once or twice and then transferred to tissue culture bottles, where it is incubated and maintained at $37^{\circ} \mathrm{C}$.

\section{Cytogenetics}

For cytogenetic analysis, three different passages of the cell line, that was in an exponential growth phase, were synchronized (19) and blocked with $0.0016 \%$ colchicine, harvested with $0.05 \%$ trypsin, treated with hypotonic solution $(0.075 \mathrm{KCl})$ for about $20 \mathrm{~min}$ at $37^{\circ} \mathrm{C}$, and fixed with $3: 1$ methanol/ acetic acid. Slides were submitted to standard Giemsa staining and trypsin-Giemsa banding (GTG-banding). The description of chromosome aberrations was based on the recommendations of the International System for Human Cytogenetic Nomenclature (ISCN 1995) (20).

\section{Results}

\section{Establishing the permanent culture}

We cultured 22 primary gastric adenocarcinomas, only one of which was immor- talized in vitro by spontaneous transformation, a biological phenomenon that enabled us to produce the ACP01 cell line.

\section{Histopathology}

The gastric lesion was classified as an intestinal-type gastric adenocarcinoma (21). According to the UICC (Union Internationale Contre Le Cancer) standardization (22), this stage was classified as T4N2M0.

\section{Morphological analysis}

The passages grew in an unorganized single layer, with some agglomerations (Figure 1), heterogeneous divisions (bipolar and multipolar) (Figure 2A-C), and a cell cycle approximately $40 \mathrm{~h}$ long, with maximum confluence at $74 \mathrm{~h}$.

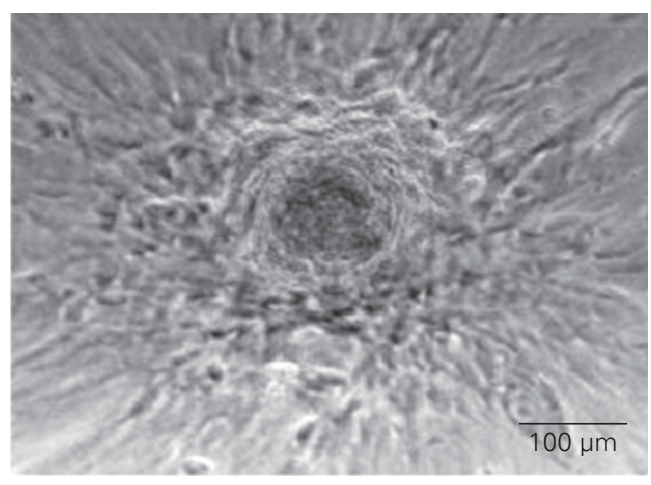

Figure 1. Formation of agglomerates in the culture of the ACP01 cell line, indicating a loss of contact or density inhibition. These cells had undergone the 12th passage (Magnification: 40X).

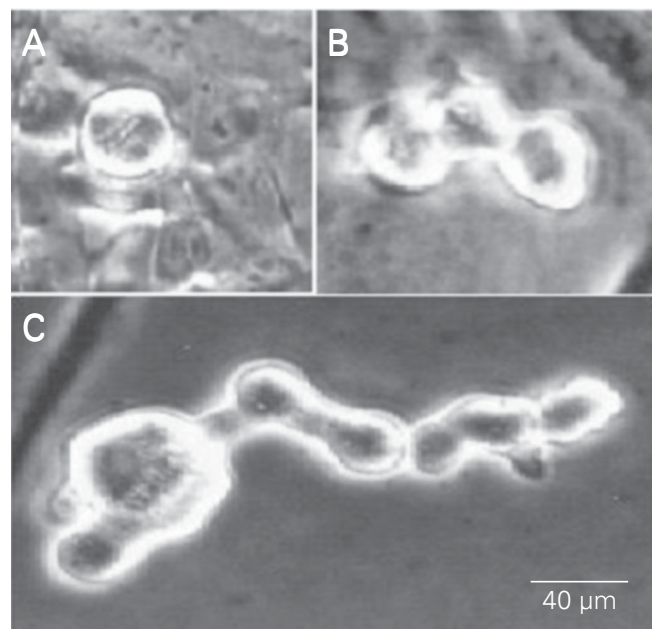

Figure 2. Heterogeneity of the lar cell division. $B$, Tripolar cell division. $C$, Multipolar cell division (Magnification: 100X). cell division of ACP01. A, Bipo- 


\section{Phase of the ACP01 cell line}

The ACP01 cell line is presently in its 63rd passage; the first stored sample was prepared at the sixth passage. We now have a stock of cells maintained in liquid nitrogen that is available to whoever is interested in working with this line.

\section{Cytogenetic analysis}

Chromosome analyses were carried out on three different passages (6th, 12th, and 35th).

Distribution of chromosome numbers. Analysis of the modal number revealed that the ploidy of the ACP01 cell line evolved

Table 1. Distribution of the number of chromosomes per cells in the different cell generations (passages) of ACP01.

\begin{tabular}{lccc}
\hline & \multicolumn{3}{c}{ Passage } \\
\cline { 2 - 4 } & 6 th & 12 th & 35 th \\
\hline VCN & $37-52$ & $40-100$ & $54-102$ \\
Haploid 23-34 (\%) & $0 \%$ & $0 \%$ & $0 \%$ \\
Diploid 35-57 (\%) & $100 \%$ & $53.33 \%$ & $6.06 \%$ \\
Triploid 58-80 (\%) & $0 \%$ & $33.33 \%$ & $87.88 \%$ \\
Tetraploid 81-103 (\%) & $0 \%$ & $13.34 \%$ & $6.06 \%$ \\
Modal number (MN) & 44 & 64 & 64 \\
No. MN & 15 & 10 & 15 \\
No. TMA & 34 & 30 & 33 \\
\hline
\end{tabular}

The data in the table are based on the observation of chromosome number per cells for each passage. $\mathrm{VCN}$ = variation in chromosome number; $\mathrm{MN}=$ number of metaphases with the modal number of chromosomes; TMA = total number of metaphases analyzed.

Table 2. Composite karyotypes of the 6 th, 12 th and 35 th generations of cells of cell line ACP01.

\begin{tabular}{llc}
\hline Passages & Composite karyotypes & Number of cells \\
\hline 6th & $34-56, X X,+1(6),+3(6),+7(6),+8(12)$, & 20 \\
& $-9(4),-12(8),-19(8),-X(3)(c p 20)^{1}$ & 20 \\
12 th & $58-95, X X X$ & 20 \\
35th & $60-102, X X X$ &
\end{tabular}

${ }^{1}$ Number of cells with clonal alteration. All cells analyzed presented chromosomal aberrations. from diploid, at the 6th passage, to triploid, at the 12 th and 35 th passages, with considerably fewer diploid cells at the 35th than at the 12th passage. Each of the three passages analyzed presented chromosomal variation. This variation is shown in Table 1.

Karyotypes. Of the three passages analyzed (6th, 12th and 35th), only the 6th was diploid, which made it impossible to examine changes in chromosome numbers in the other two passages (20). Twenty metaphases of each passage were analyzed by GTGbanding. The composite karyotypes of each passage are shown in Table 2. No normal cells $(46, X Y)$ were found in our analysis. As a control we used healthy gastric tissue from a different patient, cultured for the same time, presenting a 46,XY karyotype in all 25 metaphases analyzed.

\section{Discussion}

\section{Senescence and cellular morphology of the ACP01 cell line}

Normal cells can divide in vitro only a limited number of times, and this is called replicative senescence or senescence. Tumor cells, however, are generally immortal, and therefore they do not undergo senescence when cultured in vitro (23). According to the "Hayflick limit", the maximum number of passages that a normal cell attains before senescence is about 50; this number was determined using normal fetal fibroblasts $(24,25)$. At this time, line ACP01, established from a gastric adenocarcinoma tissue sample, has reached the 63rd passage. According to previously published reports, fibroblasts from healthy adults aged 40-50 years go through an average of 30 passages before reaching senescence (26).

On the basis of these data, it seems evident that the cells originated from the tumor tissue sample became immortalized in vitro, since the patient from whom this material was obtained was 48 years old when the 
surgery was performed. We can therefore affirm that this cell population had not entered senescence.

The cells presented unorganized growth in a monolayer, with some agglomerations, were similar to fibroblasts, and their division was heterogeneous (bipolar and multipolar), characteristics which make line ACP01 similar to other cell lines like the ones from the primary gastric adenocarcinomas (OACP4 C, MKN7, MKN74, and MKN28) and from a lymph node metastasis (OACM4.1 C) $(15,27)$. Walen (28) suggested that these morphological characteristics might be indicators of the process of in vitro immortalization, supporting the conclusion that ACP01 had been immortalized. It should be pointed out that only 14 of the 59 cell lines that have been reported are from primary tumors, and that their morphological characteristics are similar to those found in our cell line (10, 14,15).

Among the morphological characteristics observed, it is very important to draw attention to the disorganized growth of this cell line and to the formation of agglomerates, phenomena that occur due to a loss of contact inhibition or of density-based growth control $(28,29)$.

The cellular cycle of this line was about $40 \mathrm{~h}$, with maximum confluence at $74 \mathrm{~h}$. We reached this conclusion by daily monitoring the in vitro mitotic activity after each passage. Comparing the cell cycle of line ACP01 with others described in the literature, we can conclude that the duration of the cell cycle in gastric malignancies is heterogeneous. For example, line KSGH9201 has a quite short cell cycle, with cells dividing at intervals of about $34 \mathrm{~h}$ (30), while line KATOII has a cell cycle of more than $74 \mathrm{~h}$ (10).

All of these data confirm that heterogeneous proliferation occurs in cancer, the degree of heterogeneity depending on the stage of the disease at the time when the tumor is removed. However, after the point where ACP01 cells are no longer subject to senes- cence (after 30 passages), the cycle stabilizes at around $40 \mathrm{~h}$.

\section{Cytogenetic characterization and clonal evolution of the ACP01 cell line}

The cytogenetic analysis of transformed cell lines at various passages is an excellent tool for the study of clonal evolution of malignant diseases $(10,15)$. We analyzed three different passages (6th, 12th, 35th) of cell line ACP01. At the 6th passage, the cell suspension was still in the primary culture phase; the 12th passage was a long-duration phase, and, at the 35th passage, the culture was already an established line. Therefore, the passages that we examined represent the different stages of development of a cell line.

No normal karyotype was found in any of the passages analyzed. This fact strengthens the hypothesis that, from the 6th passage on, only neoplastic cells were cultured, with the normal cells degenerating due to senescence during the first five passages or during the cryopreservation procedure.

The cytogenetic data of the 6th passage, which corresponds to a short-duration culture, can be compared to published karyotype data on primary stomach tumors (4). Chromosome alterations in this passage had already been described for this histological type of tumor, such as trisomies $1,3,7,8$, and 9 (7-9). In our sample, the most frequent of these alterations was trisomy 8 , found in $60 \%$ of the cells (Table 1). An important point is that chromosome 9 monosomy, found in $20 \%$ of the cells of this passage, is among the most frequently reported $(5,9,31)$. The proto-oncogene $c$-myc is located on chromosome 8 . This gene has recently been considered to be important in apoptosis induced by proto-oncogenes in human tumors (32). Previous reports, together with the information obtained in the present study, suggest that chromosome trisomy, associated or not with other chromosome aberrations, starts in less advanced stages of the disease, at times even 
before the appearance of metastases (9).

The 12th passage, which is a long-duration cell culture cycle, was characterized mainly by the presence of triploid cells; therefore we can deduce that clonal evolution of line ACP01 occurred through polyploidization from diploid after the 6th passage to triploid after the 12th passage.

Atkin (33) suggested that polyploidization could be a characteristic of carcinogenesis, since the aggressiveness of a cancer is related to the degree of genomic instability, associated with chromosome selection. Therefore, the increase in the population of polyploid cells could be a genetically unstable intermediate stage during the progression of many types of cancer (28).

We believe that the polyploidization in line ACP01 arose through cellular endoreduplication. This hypothesis is based on the fact that we observed a large number of endoreduplicated cells (Figure 3). Non-programmed proliferation of cells that grow relatively fast can accumulate various errors. The high mitosis rate can alter the process of chromosome organization or chromosome connection to the spindle fibers, causing chromosome alterations such as endoreduplication $(28,34)$.

The 35th passage involves cells that have passed the limit of senescence (26). Cytogenetic analysis revealed the maintenance of triploid cells and a decrease in the number of diploid cells, which were still present at the 12th passage.

Figure 3. Polyploidization by endoreduplication in ACP01, a cell line established from a primary human gastric tumor.

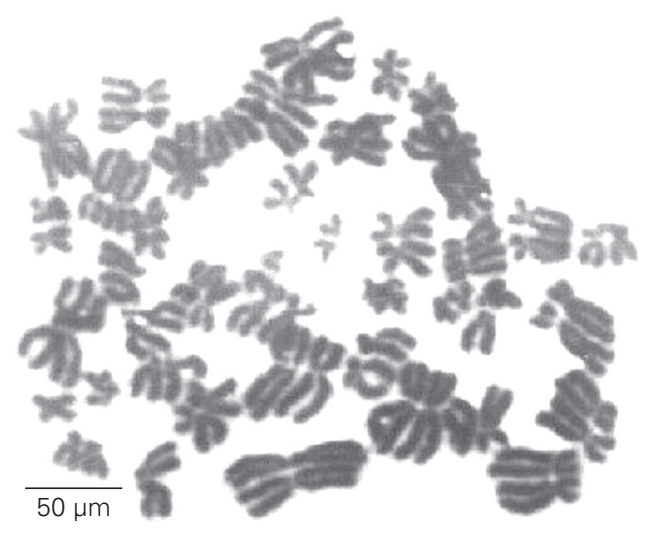

Many of the triploid and/or tetraploid cells found in the 12th as well as in the 35th passage did not have 69 or 92 chromosomes (perfect polyploids), but rather numbers close to these. To explain this phenomenon, we should consider the process of polyploidization in solid tumors, in which the loss or gain of chromosomes is random. This model suggests that polyploidization plays a key role in the evolution of the disease, given its high degree of aggressiveness $(28,35,36)$. Abarbanel et al. (8), who performed a cytogenetic analysis of various gastric tumors, found triploids and tetraploids in advanced stages of the disease, with cytogenetic alterations being more complex in more advanced phases of the tumor.

We did not detect any clonal marker chromosomes or double minutes, which are commonly found in human tumor lines. It seems likely that, in passages exceeding the 35th, such aberrations are seen in a clonal form. In one cell, non-clonal structural alterations were found involving chromosomes 1, 9, and 17. It is possible that clonal expansion can fix such structural alterations in the cell population in subsequent mitoses or that, on the other hand, these aberrations do not provide any adaptive advantage to the cells in transformation and therefore are eliminated. We believe that the latter hypothesis is correct, since the structural alterations were found only in the 6th passage, but not in the 12 th or the 35 th.

As the tumor line $\mathrm{ACP} 01$ presented aneuploidies, it may be considered a prospect towards the application of molecular cytogenetic techniques, mainly comparative genomic hybridization, which would allow a more detailed analysis of chromosome losses and gains in this cell line.

The characteristics of the ACP01 cell line described here show that the development of stomach cancer is multifactorial and passes through multiple stages involving progressive genetic changes and clonal expansion. 


\section{Acknowledgments}

The authors are indebted to Dr. Julio Pieczarka and Dr. Cleusa Nagamashi (De-

\author{
partment of Genetics, UFPA) for laboratory \\ support. Thanks are also due to Ms. Glorita \\ Santos (Department of Biology, UFPA) for \\ technical help.
}

\section{References}

1. Cancer Databases and Other Resources. International Agency for Research on Cancer (IARC) page. [http://www.iarc.fr> 2001]. Accessed September 25, 2003.

2. Pisani P, Parkin DM, Bray F \& Ferlay J (1999). Erratum. Estimates of the worldwide mortality from 25 cancers in 1990. International Journal of Cancer, 83: 18-29.

3. Estimativa de Incidência e Mortalidade por Câncer no Brasil - 2002. Instituto Nacional do Câncer (INCA) page. [http://www.inca.org.br> 2002]. Accessed September 25, 2003.

4. Mitelman Database of Chromosome Aberrations in Cancer. National Center for Biotechnology Information (NCBI) page. [http:// cgap.nci.nih.gov/Chromosomes/Mitelman]. Accessed Setember 25, 2003.

5. Assumpção PP, Burbano RR, Lima EM, Araujo M, Harada ML, Demachki S \& Ishak G (2001). Chromosomal aberrations in gastric cancer. 4th International Gastric Cancer Congress 2001, New York, USA, International Proceeding Division. Monduzzi Editore, Roma, 857-861.

6. Chun YH, Kil JI, Suh YS, Kim SH, Kim H \& Park SH (2000). Characterization of chromosomal aberrations in human gastric carcinoma cell lines using chromosome painting. Cancer Genetics and Cytogenetics, 119: 18-25.

7. Panani AD, Ferti A, Malliaros S \& Raptis S (1995). Cytogenetic study of 11 gastric adenocarcinomas. Cancer Genetics and Cytogenetics, 81: 169-172.

8. Abarbanel J, Shabtai F, Kyzer S \& Chaimof C (1991). Cytogenetic studies in patients with gastric cancer. World Journal of Surgery, 15: 778-782

9. Xia JC, Lu S, Geng JS, Fu SB, Li P \& Liu QZ (1998). Direct chromosome analysis of ten primary gastric cancers. Cancer Genetics and Cytogenetics, 102: 88-90.

10. Sekiguchi M, Sakakibara K \& Fujii G (1978). Establishment of cultured cell lines derived from a human gastric carcinoma. Japanese Journal of Experimental Medicine, 48: 61-68.

11. Park JG \& Gazdar AF (1996). Biology of colorectal and gastric cancer cell lines. Journal of Cellular Biochemistry, 24 (Suppl): 131-141.

12. Terano A, Nakada R, Hiraishi H, Ota S, Mutoh H, Shimada T, Shiina S, Itoh Y, Shiga J \& Sugimoto T (1989). Establishment of a new cell line derived from human gastric adenocarcinoma, producing tumor markers. Gastroenterologia Japonica, 24: 219.

13. Ihara A (1992). Establishment and characterization of a new poorly differentiated gastric cancer cell line (MKK-1), derived from Borrmann type 3 tumor. Nippon Shokakibyo Gakkai Zasshi, 89: 2645-2654.

14. Vollmers HP, Stulle K, Dammrich J, Pfaff M, Papadopoulos T, Betz C, Saal K \& Muller-Hermelink HK (1993). Characterization of four new gastric cancer cell lines. Virchows Archiv. B. Cell Pathology Including Molecular Pathology, 63: 335-343.

15. De Both NJ, Wijnhoven BP, Sleddens HF, Tilanus HW \& Dinjens
WN (2001). Establishment of cell lines from adenocarcinomas of the esophagus and gastric cardia growing in vivo and in vitro. Virchows Archiv, 438: 451-456.

16. Dai Y, Lin H, Yuan L, Li J, Li Y, Chen G \& Li J (2000). Establishment and characteristics of a human signet ring cell gastric carcinoma cell line (SJ-89) under serum-free conditions. In Vitro Cellular and Developmental Biology. Animal, 36: 629-630.

17. Maunoury R (1977). Establishment and characterization of 3 human cell lines derived from intracerebral metastatic tumors. ComptesRendus Hebdomadaires des Séances de l'Académie des Sciences. Série D, Sciences Naturelles, 284: 991-994.

18. Barranco SC, Townsend Jr CM, Casartelli C, Macik BG, Burger NL, Boerwinkle WR \& Gourley WK (1983). Establishment and characterization of an in vitro model system for human adenocarcinoma of the stomach. Cancer Research, 43: 1703-1709.

19. Yunnis JJ (1981). New chromosome techniques in the study of human neoplasia. Human Pathology, 12: 540-549.

20. Mitelman F (1995). ISCN: An International System for Human Cytogenetics Nomenclature. S. Karger, Basel, Switzerland.

21. Lauren $P$ (1965). The two histological main types of gastric carcinoma: diffuse and so-called intestinal-type carcinoma. Acta Pathologica et Microbiologica Scandinavica, 64: 31-49.

22. Union Internationale Contre Le Cancer (1997). TNM Classification of Malignant Tumor. Wiley \& Sons, Inc., Jersey City, NJ, USA.

23. Reddel RR (2000). The role of senescence and immortalization in carcinogenesis. Carcinogenesis, 21: 477-484.

24. Rubin $H$ (2002). Promise and problems in relating cellular senescence in vitro to aging in vivo. Archives of Gerontology and Geriatrics, 34: 275-286.

25. Young J \& Smith JR (2000). Epigenetic aspects of cellular senescence. Experimental Gerontology, 35: 23-32.

26. Cristofalo VJ, Allen RG, Pignolo RJ, Martin BG \& Beck JC (1998). Relationship between donor age and the replicative lifespan of human cells in culture: A reevaluation. Proceedings of the National Academy of Sciences, USA, 95: 10614-10619.

27. Motoyama T, Hojo H \& Watanabe H (1986). Comparison of seven cell lines derived from human gastric carcinomas. Acta Pathologica Japonica, 36: 65-83.

28. Walen KH (2002). The origin of transformed cells: studies of spontaneous and induced cell transformation in cell cultures from marsupials, a snail, and human amniocytes. Cancer Genetics and Cytogenetics, 133: 45-54.

29. Timonen $S \&$ Therman $M$ (1950). The changes in the mitotic mechanism of human cancer cells. Cancer Research, 10: 431-439.

30. Shyu RY, Jiang SY, Wang CC, Wu MF, Harn HJ, Chang TM \& Yeh MY (1995). Establishment and characterization of TSGH9201, a human gastric carcinoma cell line that is growth inhibited by epidermal growth factor. Journal of Surgical Oncology, 58: 17-24.

31. Ferti-Passantonopoulou AD, Panani AD, Vlachos JD \& Raptis AS 
(1987). Common cytogenetic findings in gastric cancer. Cancer Genetics and Cytogenetics, 24: 63-73.

32. Lowe SW \& Lin AW (2000). Apoptosis in cancer. Carcinogenesis, 21: 485-495

33. Atkin BN (2000). Chromosomal doubling; the significance of polyploidization in the development of human tumors: possibly relevant findings on a lymphoma. Cancer Genetics and Cytogenetics, 116 : 81-83.

34. Burbano RR, Medeiros A, Bastos Jr L, Lima EM, Mello A, Barbieri
NJ \& Casartelli C (2000). Cytogenetic description of epithelial hyperplasias of the human breast. Cancer Genetics and Cytogenetics, 119: 62-66

35. Seizinger BR, Klinger HP, Junien C et al. (1991). Report of the committee on chromosome and gene loss in human neoplasia. Cytogenetics and Cell Genetics, 58: 1080-1096.

36. Shackney SE, Smith CA, Miller BW, Burholt DR, Murtha K, Giles HR, Ketterer DM \& Pollice A (1989). Model for the genetic evolution of human solid tumors. Cancer Research, 49: 3344-3354. 